\title{
Semen banking-is it now feasible for captive endangered species?
}

\author{
W. V. Holt and H. D. M. Moore
}

This article proposes that serious consideration should now be given to the establishment of banks of genetic material from rare and endangered species. In the light of advances in the technology associated with semen assessment and preservation, the limitations that have so far discouraged the practice of semen freezing and banking can now be minimized and circumvented. The authors review these developments and suggest that semen preservation should be reconsidered as a practical means of preserving the genetic diversity currently contained within captive stocks of wild animals.

The World Conservation Strategy published by the International Union for Conservation of Nature and Natural Resources (IUCN) in 1980 identified the preservation of genetic diversity as an important priority, both for conservation and the future development of scientific and industrial innovation. In order to implement this principle we need to make the best use of new technological progress where appropriate. The last decade has seen many developments in the technology associated with animal reproduction. Ironically, much of the stimulus for this work has arisen through the need for human infertility treatments and greater agricultural efficiency. It is appropriate, therefore, to use the fruits of this research in conservation, countering the effects of world-wide population pressures.

The purpose of this review is to outline ways in which new advances in artificial insemination technology and genetics could now be applied to achieve this end with mammalian species; we recognize that conservation of other phyla is equally important, but these will not be discussed here. In particular this article proposes that serious consideration should now be given to the idea of setting up an international repository of frozen semen from endangered species; ten years ago the technology for semen assessment 172 and freezing was not sufficiently advanced to permit such a venture but considerable progress has been made since then. Given the current rate of scientific development and innovation, the view expressed by Foose et al. (1985), that another two centuries of research will be required before germplasm banking is a realistic possibility, is unduly pessimistic.

International co-operation in the maintenance by zoos of detailed studbooks, such as those for the Arabian oryx and Przewalski's horse, means that the relative contribution of particular founder or parent animals to the current gene pool can be calculated. Certain individuals may contribute excessively, minimally or not at all; these effects, which limit the gene pool for subsequent generations, need to be countered by planned breeding programmes (for examples, see Chesser et al, 1980; Foose, 1980). These typically involve the expensive and stressful transport of animals, but artificial insemination and embryo transfer technology can be used both to avoid this procedure and to amplify the international distribution of valuable genetic resources. Furthermore, recent developments in molecular biology should facilitate the genetic analysis of populations and assist with the unequivocal identification of parent-offspring relationships.

Oryx Vol 22 No 3, July 1988 


\section{Artificial insemination in endangered species}

Ten years ago artificial insemination and semen freezing in cattle breeding were already established procedures, and some advocates of their application in conservation were rather naïvely optimistic about applying the techniques to other species. Hence, some zoos started to collect and freeze semen from a wide range of species, without due regard to the problems of using the semen for insemination. These are underlined when it is considered that, after more than 30 years of research farmers still do not use frozen ram or boar semen for breeding because the success rate is uneconomically low.

Despite these problems, artificial insemination has been successfully performed in a number of species (Table 1), and the secret of success seems to lie in the careful monitoring of semen quality and timing of inseminations. Since the economic aspects of artificial insemination are of minor importance when the aim is propagation of a rare species, the conservationist is not constrained to use minimal sperm numbers in insemination doses, and considerable care can be taken in introducing the spermatozoa into the female reproductive tract. Catheters to deliver semen samples can be guided through the cervix, or directly into the uterine horns, under visual control of the operator using fibreoptic endoscopes developed for surgical procedures. These procedures lead to improved pregnancy rates, compensating for the damaging effects of freezing upon sperm longevity and vigour.

\section{Advances in semen assessment}

Faced with a fresh or frozen semen sample, it is necessary to evaluate its fertilization potential in order to avoid spending large sums on preserving semen that stands minimal chance of ever achieving a pregnancy. Clearly, attempting to predict fertility without performing direct trials is a major problem, but techniques to achieve this end are currently under development.

Since sperm movement is one of the most obvious characteristics of a semen sample, and is essential both for sperm colonization of the cervix and oviduct prior to fertilization as well as Semen banking for captive endangered species
Table 1. Mammalian species that have been successfully bred by artificial insemination

\begin{tabular}{|c|c|c|c|}
\hline \multirow[t]{3}{*}{ Primates } & \multicolumn{3}{|l|}{ Baboon } \\
\hline & Chimpanzee & $\begin{array}{l}\text { Pan troglo- } \\
\text { dutes }\end{array}$ & $\begin{array}{l}\text { Fritz, 1986; } \\
\text { Martin et al }\end{array}$ \\
\hline & Gorilla & $\begin{array}{l}\text { Gorillag. } \\
\text { gorilla }\end{array}$ & $\begin{array}{l}1978 . \\
\text { Douglass, } \\
1981\end{array}$ \\
\hline \multirow[t]{3}{*}{ Carnivores } & Cheetah & $\begin{array}{l}\text { Acinoyx } \\
\text { jubatus }\end{array}$ & \\
\hline & $\begin{array}{l}\text { Puma } \\
\text { Snow } \\
\text { leopard }\end{array}$ & $\begin{array}{l}\text { Felis concolor } \\
\text { Panthera } \\
\text { uncia }\end{array}$ & $\begin{array}{l}\text { Moore et al., } \\
1981\end{array}$ \\
\hline & Fox & Unspecified & $\begin{array}{l}\text { Aamdal et al., } \\
1978\end{array}$ \\
\hline \multirow[t]{4}{*}{ Ungulates } & Addax & $\begin{array}{l}\text { Addax } \\
\text { nasoma- } \\
\text { culatus }\end{array}$ & $\begin{array}{l}\text { Densmore } \\
\text { et al., } 1987\end{array}$ \\
\hline & Blackbuck & Antilope & Holt et al., \\
\hline & $\begin{array}{l}\text { Speke's } \\
\text { gazelle } \\
\text { Red deer }\end{array}$ & $\begin{array}{l}\text { Gazella } \\
\text { spekei } \\
\text { Cervus } \\
\text { elaphus }\end{array}$ & $\begin{array}{l}\text { Boever et al., } \\
1980 \\
\text { Krzywinski and } \\
\text { Jaczewski, } \\
1978\end{array}$ \\
\hline & Wapiti & $\begin{array}{l}\text { Cervus } \\
\text { elaphus }\end{array}$ & $\begin{array}{l}\text { Haigh et al., } \\
1984\end{array}$ \\
\hline Others & Giant panda & $\begin{array}{l}\text { Ailuropoda } \\
\text { melanoleuca }\end{array}$ & $\begin{array}{l}\text { Moore et al., } \\
1984\end{array}$ \\
\hline
\end{tabular}

for penetrating the tough outer layers that surround the ovum, it has always seemed reasonable to regard sperm motility as a good indicator of fertility. Unfortunately, the commonest method of rating sperm motility has always been to examine a drop of semen through the microscope, making some subjective estimate of motility based on a simple scoring system. This technique is open to many pitfalls, and has provided little hard evidence for relationships between motility and fertility.

Recent research has shown, however, that sperm motility can be measured objectively using either time-lapse photography or newer computerized techniques to analyse images. Measurements of sperm swimming speed (Milligan et al., 1980; Aitken et al., 1982; Holt et al., 1985) established that, for human sperm, swimming speed was a very valuable guide to fertility in vitro and in vivo. This now forms the basis of a diagnostic test for fertility, and there is every reason to believe that it could be usefully applied to semen from the great apes. So far it has not been possible to validate this technique for ungulates, although data gathered in the Institute of Zoology, Zoological Society of London, show 173 
that blackbuck, Père David's deer and oryx spermatozoa exhibit sensitive alterations of swimming speed in response to different diluting media, as well as to cooling and freezing (see Figure 1). Published research on bull semen

(a) Arabian oryx
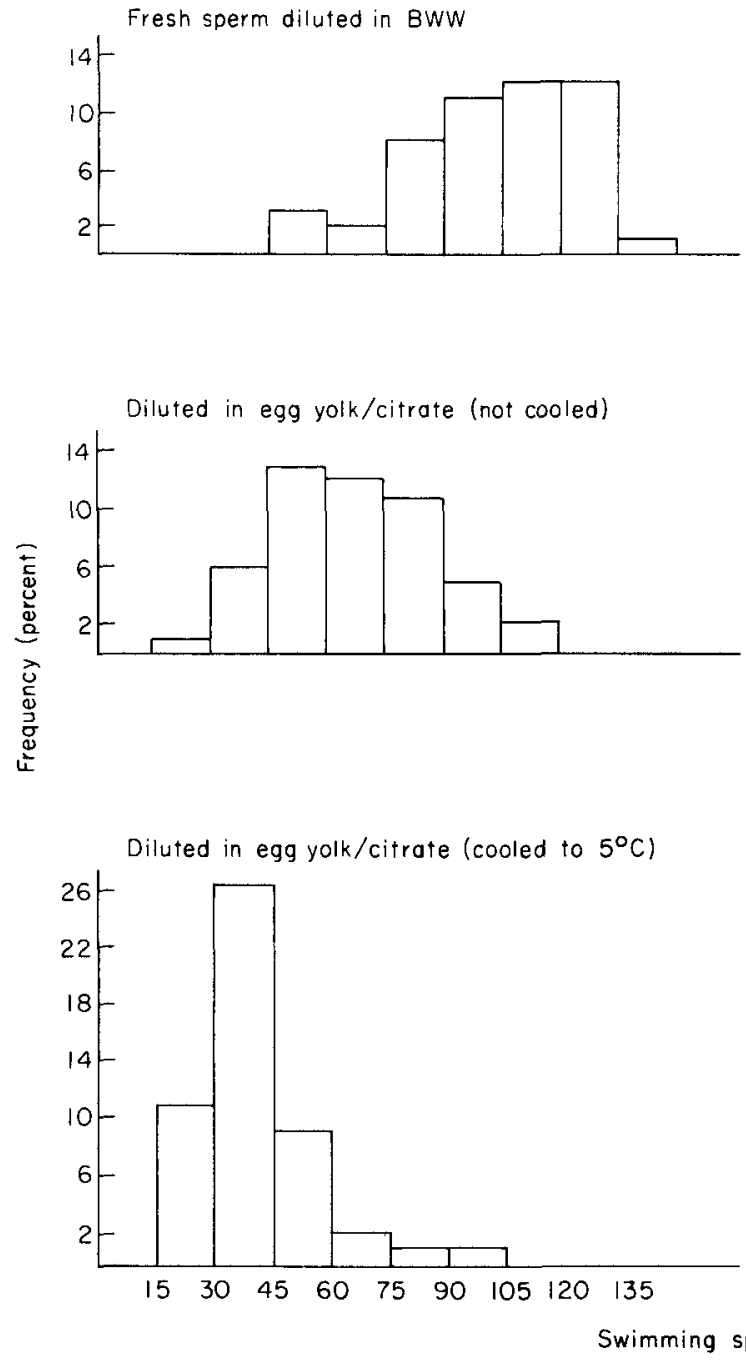

Figure 1. Frequency histograms showing how the swimming speeds of spermatozoa from (a) Arabian oryx and (b) Pere David's deer responded to the various stages of processing involved in semen freezing. Typically, these entail dilution in a cryoprotective medium containing egg yolk and glycerol, slow cooling to approximately $5^{\circ} \mathrm{C}$, then freezing in liquid nitrogen vapour. After thawing, Père David's deer spermatozoa, which showed little change in speed during processing, recovered full motility. In this example, the poor survival of Arabian oryx spermatozoa was indicated by their serious decline in swimming speed during processing. Frozen/thawed sperm were non-motile. (BWW refers to a physiologically balanced salt solution.) 
solved readily using the sophisticated computer techniques available today.

Functional tests of sperm quality provide another valuable means of assessing their likely fertility. Two types of approach have been evolved that reproduce in the laboratory the natural events leading up to fertilization. Since the chances of spermatozoa reaching the fallopian tube, and hence the egg, depend largely upon their vigour and longevity, it has been found that monitoring their progress through materials such as cervical mucus, bovine serum albumin or gel filtration media (Sephadex) provides a good indication of their fertility. A recent example of the Sephadex technique was provided in a study of water buffalo semen (Heuer et al., 1987), where a 7 per cent difference in fertility between samples collected in June and November was reflected in a superior (nearly double) ability of November samples to traverse the gel.

The second type of functional test is directed towards assessing the ability of spermatozoa to undergo the preliminary events of fertilization, then to fuse with an egg. Yanagimachi et al. (1976) reported that human spermatozoa were able to penetrate the membrane of the hamster egg, which had had its tough outer coating (zona pellucida) removed; since then there have been many reports showing that the hamster egg is unusual in not blocking the penetration of spermatozoa from other species. Tiger, dolphin, marmoset, wallaby, Père David's deer (Figure 2) and even budgerigar spermatozoa have penetrated the zona-free hamster egg, although further development does not occur, and the penetration mechanism for mammals closely resembles the natural process. This test provides a direct method of investigating the fertilization potential of spermatozoa and, despite the obvious drawbacks of using sperm and ova of different species in artificial media, it appears to work. So far, the main difficulty of applying this test with exotic species has been the need to develop suitable culture media for inducing fertilization to occur; this reflects the plethora of morphological and metabolic differences between spermatozoa from different species. Happily, however, progress is being made towards meeting these requirements and there is good reason to believe Semen banking for captive endangered species that a universally applicable technique may soon be developed.

\section{Design of semen freezing procedure}

On their own merit, the advances discussed above now justify establishing banks of frozen semen from endangered species, since the ability exists to assay semen quality objectively at every stage, from selecting suitable donors to checking post-thaw sperm survival and viability. Another complementary advance contributes strongly to the justification of this proposal; this is the relatively recent technical development of cryomicroscopy.

The ability to monitor resistance to freezing, from either species or individuals with particularly labile spermatozoa, means that banks of poor semen need not, and should not, be maintained. However, selectivity on this basis is fundamentally undesirable and steps to tailor the semen processing schedules for these animals need to be taken. This is where cryomicroscopy can help.

The cryomicroscope consists essentially of a sophisticated temperature control system, mounted around the specimen chamber of a light microscope. With this system, semen samples can be observed as they undergo cooling, freezing and thawing at controlled rates, and the whole sequence recorded on videotape or film. Techniques of sperm motility measurement can therefore be used to analyse the response to cooling and freezing. The small number of spermatozoa required for each freezing trial means that several different cooling rates, or diluting media, can be quickly evaluated to identify optimal procedures for any individual sample; the whole procedure thus defined can then be reproduced for bulk samples using a purpose-built freezing unit. At present, cryomicroscopes are expensive both to purchase and to maintain, and to our knowledge there are none dedicated to the preservation of gametes from endangered species. They are, however, being used for commercially directed research, where, for example, their potential for the development of fish-farming technology such as the freezing of sperm, eggs, embryos and unicellular organisms as feed has been clearly recognized. 


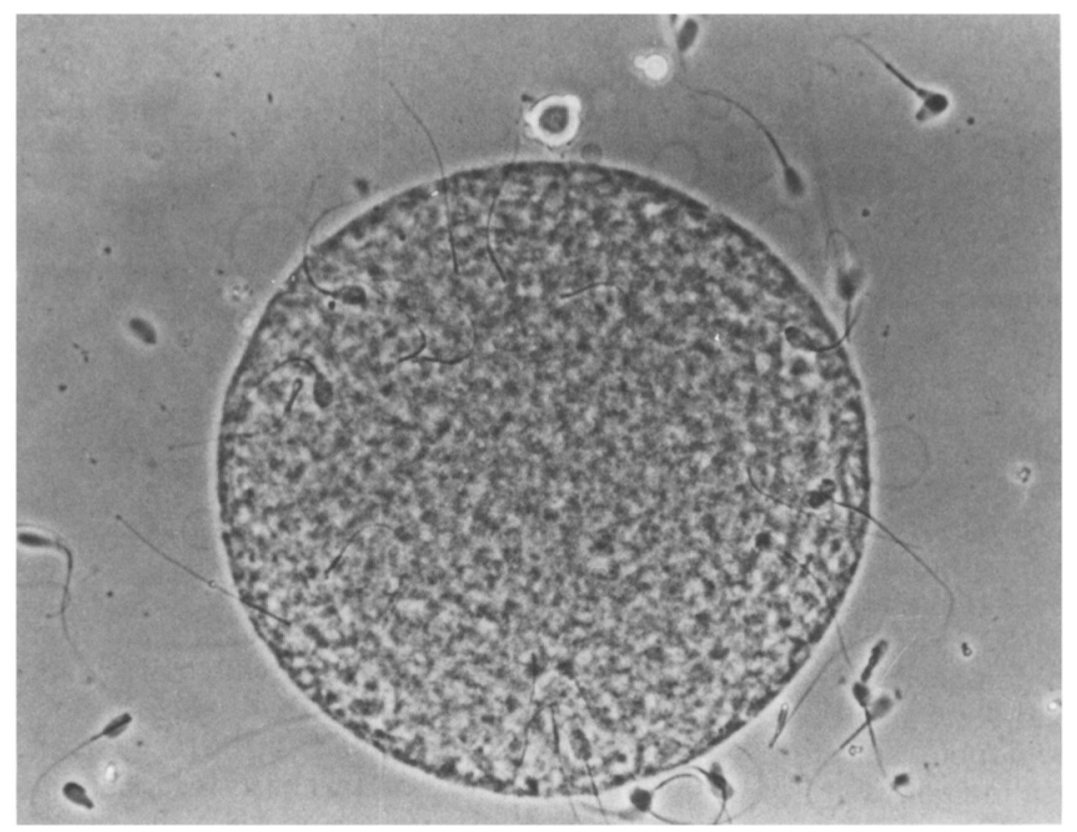

Figure 2. Photomicrograph illustrating a hamster oocyte, stripped of its zona pellucida, undergoing penetration by spermatozoa from a Père David's deer. Many sperm tails are visible, although some of the sperm heads have undergone decondensation.

\section{Insemination timing}

To perform artificial inseminations successfully requires not only effective means of preserving and handling semen, but also knowledge of the female reproductive cycle. Egg development is not a continuous process like spermatogenesis, therefore unless spermatozoa are introduced to the female reproductive tract at an appropriate time, i.e. several hours either side of ovulation, the insemination will almost certainly be unsuccessful. Fortunately, many female mammals are only sexually receptive for a relatively short period (oestrus) before ovulation, and the simple expedient of observing receptivity to a vasectomized male is often sufficient for determining the time of oestrus. In our own experience with artificial insemination in the blackbuck Antilope cervicapra it was possible to determine oestrus in about 50 per cent of the females observed. However, the cyclic production of steroid hormones during the oestrous cycle can be monitored readily by urine analysis using radioimmunoassay (see Hodges and Eastman, 1984), or techniques based on bioluminescence.

Continuous monitoring of the reproductive cycle is a tedious and inefficient process; the use of 176 certain hormones such as prostaglandins and progesterone to bring a female into oestrus bypasses the need for monitoring and allows the time of insemination to be planned ahead. This has an added advantage in farming practice where the insemination times for all cows in a herd can be synchronized. With some knowledge of the natural oestrous cycle, this treatment can, in principle, be used for controlling the time of insemination in most ungulates. It has already been used successfully for addax (Densmore et al., 1987), scimitar-horned oryx and Père David's deer. Suitability of the procedure does need to be confirmed for each new species tried, however, to establish that prostaglandins do not interfere with egg development and ovulation. Outside the range of ungulates the application of this method is less uniform, as some species do not respond to prostaglandin treatment.

\section{Genetic aspects of semen banking}

Since the purely technical problems that previously discouraged zoos from establishing semen banks for endangered species can now be largely circumvented, there is currently every reason for pursuing this policy. At least two more funda-

Oryx Vol 22 No 3, July 1988 
mental questions need to be addressed, however; how do we select animals as semen donors, and what proportion of the current gene pool should be conserved?

The answers to these questions will differ for each species, being dependent partly upon existing population size and partly upon inter-generation intervals. For example, if semen storage from Arabian oryx is to be considered then the pedigrees of individuals in the current world herd needs to be considered. The records for this species, which have been well kept for many years (Mace, 1986), indicate that certain males have sired few offspring while others have produced a disproportionately large number. Should we aim to store the semen from the least successful males, so that their genetic contribution is not lost and can eventually be reintroduced into the bloodline? Conversely, should we concentrate on the most successful animals?

Recent advances in genetics should help with some of these problems. Firstly, it is necessary to know that stud book records are correct, or where stud books do not exist, to possess the capability for assessing the proportion of the current gene pool represented by a particular individual. New DNA fingerprinting techniques are now being used to confirm paternity in humans. Some of these probes are effective with other species, particularly the great apes, as well as sheep, mice and even sparrows (Burke and Bradford, 1987; Wetton et al., 1987). Although the use of these probes with unusual species needs validation, they would be useful for providing unequivocal identification of individuals. Tracing of maternal lineages by analysis of mitochondrial DNA has also been proposed (for review see Powell, 1983); this approach is justified by the observation that only maternally derived mitochondria are passed from one generation to the next. Study of mitochondrial DNA also has the advantage that it can be used to probe evolutionary distance between different populations of similar species (Brown et al., 1979); in a recent review Benirschke (1983) cited a study of two subspecies of white rhinoceros, where comparison of fragments obtained from mitochondrial DNA allowed the divergence to be estimated at two million years ago.

Semen banking for captive endangered species
Studies of genetic variation have been performed biochemically for many years using the slight molecular differences between proteins as markers of lineage; thus surveys have, for example, been performed upon the genetic variability between geographically separate populations of animals such as reindeer, cheetah, Przewalski's horse and many other species (for review see Powell, 1983). Techniques of this nature, together with the newer methods in molecular biology, will provide the information for making judgements regarding the relative genotypic value of semen donors. This link between genetics and semen preservation is essential, given the ultimate aim of maintaining genetic diversity.

\section{Conclusions}

The ultimate goal of conservation, captive breeding and semen banking is clear; to preserve the vigour and viability of species so that they do not decline and drift, eventually becoming unable to sustain themselves. Ideally, it will be possible to reintroduce species into their native habitat; some projects like Operation Oryx have already been undertaken, but the need for genetic management is unlikely to disappear. Planned breeding programmes will not fulfil the need to preserve sufficient genetic diversity for optimal survival of endangered species, and there is a definite requirement for the application of technology in this area. It should be remembered that frozen semen retains its viability for many decades, which provides an opportunity to plan for artificial inseminations several generations ahead, thus regaining some of the genetic traits lost during the intervening period.

The separation of $\mathrm{X}$ and $\mathrm{Y}$ chromosome-bearing spermatozoa is not yet possible, but the development of such technology is likely within the next decade as the influence of sex chromosomes upon the cell surface chemical architecture becomes clearer. Such an innovation would enable the managers of the future to choose the sex of offspring, perhaps in accordance with a predetermined breeding programme. It is not too early to give some consideration to the implications of this research, which could be used to the benefit of endangered species. 
This review has not dealt with the preservation of embryos, and embryo collection and transfer, all of which are feasible in species like the cow, sheep and horse, and which are, in theory at least, applicable to endangered species. On a purely practical basis the widespread application of these procedures is unlikely, in view of the high level of technical support and expertize required to perform both embryo collection and transfer. There is undoubtedly a case, where possible, however, for obtaining and storing genetic material in the form of embryos, especially as closely related, but more common, species can sometimes be used as hosts to produce the live offspring.

\section{References}

Aamdal, J., Fougner, J. and Nyberg, K 1978. Artificial insemination in foxes. In Symp. Zool. Soc. Lond. (ed. P.F. Watson), pp. 241-248. Academic Press, London.

Aitken, R.J., Best, S.M., Richardson, D.W., Djahanbakhch, O., Mortimer, D., Templeton, A.A. and Lees, M.M. 1982. An analysis of sperm function in cases of unexplained infertility: conventional criteria, movement characteristics, and fertilizing capacity. Fertil. Steril. 38, 212-221.

Benirschke, K. 1983. The impact of research on the propagation of endangered species in zoos. In Genetics and Conservation. A Reference for Managing Wild Animal and Plant Populations (eds C.M. Schonewald-Cox, S.M. Chambers, B. MacBryde and W.L. Thomas), pp. 402413. Benjamin/Cummings, Menlo Park.

Boever, J., Knox, D., Merilan, C.P. and Read, B.W. 1980. Estrus induction and artificial insemination with successful pregnancy in Speke's gazelle. In Proc. 9th Int. Congr. Anim. Reprod. Artif. Insem. Madrid, pp. 565-569.

Brown, W.M., George, M.J.R. and Wilson, A.C. 1979. Rapid evolution of animal mitochondrial DNA. Proc. Natl. Acad. Sci. USA, 76, 1967-1971.

Burke, T. and Bradford, M.W. 1987. DNA fingerprinting in birds. Nature Lond. 327, 149-152.

Chesser, R.K., Smith, M.H. and Brisbin, I.L. 1980. Management and maintenance of genetic variability in endangered species. In Int. Zoo Yearbook (ed. P.J.S. Olney). pp. 146-154. Zoological Society of London, London.

Densmore, M.A., Bowen, J., Magyar, S.J., Amoss Jr, M.S., Robinson, R.M., Harms, P.G. and Kraemer, D.C. 1987. Artificial insemination with frozen, thawed semen and pregnancy diagnosis in Addax Addax nasomaculatus. Zoo. Biology, 6, 21-29.

Douglass, E.M. 1981. First gorilla born using artificial insemination. Int. Zoo News, 28, 9-15.

Foose, T.J. 1980. Demographic management of endangered species in captivity. In Int. Zoo Yearbook (ed. P.J.S. Olney) pp. 154-166. Zoological Society of London, London.

Foose, T.J., Seal, U.S. and Flesness, N.R. 1985. Conserving animal genetic resources. IUCN Bulletin, 16, 20-21.

178
Fritz, J. 1986. Resocialization of asocial chimpanzees. In Primates: the Road to Self-Sustaining Populations (ed. K. Benirschke), pp. 351-359. Springer-Verlag, New York.

Haigh, J.C., Shadbolt, M.P. and Glover, G.J. 1984. Artificial insemination of wapiti. Proc. Am. Ass. Zoo Vet. p. 174

Heuer, C., Tahir, M.N. and Amjad, H. 1987. Effect of season on fertility of frozen buffalo semen. Animal Reprod. Sci. 13, 15-21.

Hodges, J.K. and Eastman, S.A.K. 1984. Monitoring ovarian function in marmosets and tamarins by the measurement of urinary estrogen metabolites. Am. J. Primatol. 6, 187-197.

Holt, W.V., Moore, H.D.M. and Hillier, S.G. 1985. Computer-assisted measurement of sperm swimming speed in human semen: Correlation of results with in vitro fertilization assays. Fertil. Steril 44, 112-119.

Holt, W.V., Moore, H.D.M., North, R.D., Hartman, T.D. and Hodges, J.K. 1988. Hormonal and behavioural detection of oestrus in blackbuck, Antilope cervicapra, and successful artificial insemination with fresh and frozen semen. $J$. Reprod. Fert. 82, 717-725.

Krzywinski, A. and Jaczewski, Z. 1978. Observations on the artificial breeding of red deer. In Symp. Zool. Soc. Lond. (ed. P.F. Watson), pp. 271-287. Academic Press, London.

Mace, G.M. 1986. Genetic management of small populations. In Int. Zoo Yearbook (ed. P.J.S. Olney), pp. 167174. Zoological Society of London, London.

Martin, D.E., Graham, C.E. and Gould, K.G. 1978. Successful artificial insemination in the chimpanzee. In Symp. Zool. Soc. Lond. (ed. P.F. Watson). pp. 249-260. Academic Press, London.

Milligan, M.P., Harris, S. and Dennis, K.J. 1980. Comparison of sperm velocity in fertile and infertile groups as measured by time-lapse photography. Fertil. Steril. 34, 509-511.

Moore, H.D.M., Bonney, R.C. and Jones, D.M. 1981. Successful induced ovulation and artificial insemination in the puma Felis concolor. Vet. Rec. 108, 282-283.

Moore, H.D.M., Bush, M., Celma, M., Garcia, A.-L., Hartman, T.D., Hearn, J.P., Hodges, J.K., Jones, D.M., Knight, J.A., Monsalve, L. and Wildt, D.G. 1984. Artificial insemination in the Giant Panda. J. Zool. 203, 269-278.

Powell, J.R. 1983. Molecular approaches to studying founder effects. In Genetics and Conservation. A Reference for Managing Wild Animal and Plant Populations. (eds C.M. Schonewald-Cox, S.M. Chambers, B. MacBryde and W.L. Thomas), pp. 229-240. Benjamin/Cummings, Menlo Park.

Wetton, J.H., Carter, R.E., Parkin, D.T. and Walters, D. 1987. Demographic study of a wild house sparrow population by DNA fingerprinting. Nature, Lond. 327, 147-149.

Yanagimachi, R., Yanagimachi, H. and Rogers, B.J. 1976. The use of zona-free animal ova as a test system for the assessment of the fertilizing capacity of human spermatozoa. Biol. Reprod. 15, 471-476.

W.V. Holt and H.D.M. Moore, MRC/AFRC Comparative Physiology Research Group, Institute of Zoology, Zoological Society of London, Regent's Park, London NW1 4RY, UK.

Oryx Vol 22 No 3, July 1988 